\title{
IN VITRO DETERMINATION OF SUN PROTECTION FACTORS ON ETHANOL EXTRACT AND NANOSTRUCTURED LIPID CARRIER-BASED GEL EXTRACT OF MULBERRY ROOT (MORUS ALBA L.)
}

\author{
FAIZATUN FAIZATUN*, SHELLA DAYU ASTO \\ Department of Pharmaceutical Technology, Faculty of Pharmacy, University of Pancasila, Jakarta, Indonesia. \\ Email: faizah2776@gmail.com
}

Received: 28 February 2018, Revised: 06 April 2018 and Accepted: 16 April 2018

ABSTRACT

Objective: The purpose of this study was to determine the potential of sun protection factors on extract and nanostructured lipid carrier (NLC) gel of mulberry root extract.

Methods: In this study, the root mulberry (Morus alba L.) was extracted using $96 \%$ ethanol and tested its sun protective factor (SPF) values. Mulberry root extract made into NLC with solvent evaporation method. The NLC was evaluated and dispersed into the gel, NLC gel was tested SPF value by petro method.

Results: The result shows that the SPF value extracts of mulberry root at the concentration $300 \mathrm{ppm}, 400 \mathrm{ppm}$, and 500 ppm were $10.84,28.17$, and 66.65 , respectively. While the SPF values of NLC gel extract of mulberry root at the concentration of $300 \mathrm{ppm}, 400 \mathrm{ppm}$, and $500 \mathrm{ppm}$ were $9.11,22.87$, and 45.76, respectively.

Conclusion: It could be concluded that extract and NLC gel of mulberry root extract have potential in ultraviolet protection against the skin.

Keywords: Mulberry root extract, Sun protective factor, Nanostructured lipid carrier, Spectrophotometry.

(C) 2018 The Authors. Published by Innovare Academic Sciences Pvt Ltd. This is an open access article under the CC BY license (http://creativecommons. org/licenses/by/4. 0/) DOI: http://dx.doi.org/10.22159/ajpcr.2018.v11s1.26590

\section{INTRODUCTION}

Indonesia is known as a tropical country, where the influence of the sun is very large in the life of living beings. Sunlight provides a beneficial effect that can prevent or treat bone disorders by activating provitamin D3 (7-dehydrocholesterol) found in the skin epidermis to Vitamin D3. However, excessive exposure to sunlight can also cause adverse effects, especially on the skin due to ultraviolet (UV) rays contained therein can cause erythema, acceleration of skin aging, and even cancer [1]. Several ways can be done to prevent such adverse effects of UV ray, one of which is with the use of sunscreen. Sunscreen is a cosmetic preparation used to protect skin from exposure to sunlight by reflecting or absorbing sunlight. Sunscreen can absorb at least $85 \%$ of sunlight at $290-320 \mathrm{~nm}$ wavelengths but can continue light at wavelengths greater than $320 \mathrm{~nm}$ for UV A [1]. UV B wavelengths of 290-320 $\mathrm{nm}$ are more effective in causing skin damage than with UV A having a longer wavelength of 320$400 \mathrm{~nm}[2]$

The use of active photoprotective is very beneficial in reducing the adverse effects of UV rays. Phytoconstituent categories as UV protector include phenolic acid: Hydroxycinnamic and hydroxybenzoic acid, flavonoids: Quercetin, luteolin, and catechin, and high-molecular-weight polyphenols: Tannins, catechins or epicatechins, and ellagic acid [2]. Other photoprotective phytoconstituents include curcumin, caffeic and ferulic acid, apigenin, genistein, resveratrol, nordihydroguaiaretic acid, carnosic acid, silymarin, and others.

\section{METHODS}

\section{Chemical and reagents}

Plant has been procured from Rumah Sutera, Bogor, Indonesia, and it has been authenticated by Research Center for Biology, Indonesian Institute of Sciences, Indonesia, with the Voucher Specimen No. 1048/IPH.1.01/If.8/VII/2015. Stearic acid (SA) (PT. Sumi Asih Oleochemical Industry, Indonesia) was used as solid lipid material of NLC, virgin coconut oil(VCO) (CV. HerbaBagoes, Indonesia) was chosen as liquid lipid material for NLC, carbopol 940 (Lubrizol, USA), triethanolamine (Dow Chemical, Singapore), tween 80 and Span 80 (BASF, German).

\section{Preparations of extracts}

Each of $300 \mathrm{~g}$ powder of root was extracted by maceration combination with sonication in $96 \%$ ethanol. They were soaked at room temperature for $24 \mathrm{~h}$ and sonicated for $40 \mathrm{~min}$. The ethanolic extract was filtered through a vacuum filter and the filtrate was dried. The percentage yield of crude extract was calculated. Crude extracts were kept in the refrigerator at $4^{\circ} \mathrm{C}$.

Total flavonoid assay for the extract about $200 \mathrm{mg}$ of the simplicia, exactly weighted, was transferred to round bottom flasks and $20.0 \mathrm{~mL}$ acetone $\mathrm{R}, 1.0 \mathrm{~mL}$ of hexamethylenetetramine $0.5 \%$, and $2.0 \mathrm{~mL} 25 \%$ hydrochloric acid $\mathrm{R}$ added. The mixture was refluxed on a water bath for $30 \mathrm{~min}$. After cooling, the final volume was made up to $100.0 \mathrm{~mL}$ acetone R. $20.0 \mathrm{~mL}$ of filtrate and $20.0 \mathrm{~mL}$ water were treated once with $15.0 \mathrm{~mL}$ and 3 times with $10.0 \mathrm{~mL}$ ethyl acetate. $10.0 \mathrm{~mL}$ of ethyl acetate fraction plus $2.0 \mathrm{~mL}$ of $\mathrm{AlCl}_{3}$ ethanolic solution was made up to $25.0 \mathrm{~mL}$ with methanol/acetic acid to produce the test solution [3]. Calculation of total flavonoid uses quercetin standard.

Formulation of nanostructured lipid carrier (NLC)

NLC was prepared by the method of solvent diffusion method in an aqueous system. Extract mulberry was dissolved in acetone and then SA-VCO was mixed and kept in a water bath at $70^{\circ} \mathrm{C}$. The aqueous phase was prepared by dissolving surfactant in distilled water at $70^{\circ} \mathrm{C}$. Subsequently, the organic phase was quickly dispersed into the aqueous phase with magnetic stirring $(600 \mathrm{rpm})$ and then continued stirring with Ultra-Turrax 20,000 rpm (IKA Ultra-Turrax, T25, Germany). After removing the organic solvent, semitransparent NLC was obtained and then it was transferred into cold distilled water 
$\left(0-2^{\circ} \mathrm{C}\right)$ under stirring for $5 \mathrm{~s}$ and then performed ultrasonication $50 \mathrm{~W}$ for $15 \mathrm{~s}$

\section{Physicochemical characterization of NLC}

Particle size and zeta potential measurement

The volume average diameter and zeta potential of NLC in dispersion were determined with Zetasizer (2000HS, Malvern Instruments, UK) after diluted 20 times with distilled water.

\section{Morphology}

The microstructure of NLC was observed using transmission electron microscope (TEM, JEM-1400, JEOL, Tokyo, Japan). Initially, samples diluted with double-distilled water were deposited on a film-coated copper grid, following by stained with $1 \%$ aqueous solution of phosphotungstic acid, ultimately the superfluous phosphotungstic acid on the samples was wiped off by filter paper and the sample was allowed to dry before examined under the TEM.

\section{Formulation of NLC-based gels}

The NLC was gelled using carbopol 940. Based on the compatibility with nanoparticulate dispersion, carbopol 940 was selected as the gelling agent. Carbopol was dispersed using an overhead stirrer at the speed of $300 \mathrm{rpm}$. The carbopol dispersion was neutralized using $0.3 \%(\mathrm{w} / \mathrm{w})$ triethanolamine. Carbopol $9400.3 \%$ was added to the NLC under overhead stirring at $300 \mathrm{rpm}$. Stirring was continued till the carbopol got dispersed. Methyl and propylparaben were dissolved to propyleneglicol and then the solution was mixed with gel. Physicochemical characterization of NLC-based gel included viscosity, spreadability, flow properties, and $\mathrm{pH}$.

Determination of sun protective factor (SPF) value of extract and NLC-based gel

Extract and NLC-based gel extract of mulberry root were made the concentration of $300 \mathrm{ppm}, 400 \mathrm{ppm}$, and $500 \mathrm{ppm}$ using ethanol solvent. Determination of SPF is measuring sample absorbance using spectrophotometer at wavelength 290-400 nm. This SPF value is based on absorbance measurement data of the test material with the spectrophotometer, with minimum absorbance value 0.05 and with interval $5 \mathrm{~nm}$ so that the value of area under curve (AUC) is obtained. The absorbance value $<0.05$ is relatively unlikely to cause an erythema reaction to the skin, so it is not used for AUC calculations.

\section{SPF calculation}

The total AUC is set as follows [4]:

$$
\mathrm{AUC}=\frac{\mathrm{Aa}+\mathrm{Ab}}{2}(\mathrm{aPa}-\mathrm{b})
$$

Aa: Absorbance at wavelength a nm Ab: Absorbance at wavelength $\mathrm{b} \mathrm{nm}$ $\mathrm{dPa}-\mathrm{b}$ : Difference in wavelength $\mathrm{a}$ and $\mathrm{b}$

The total AUC value is calculated by summing all the AUC values on each wavelength segment. The SPF value is calculated by the following formula [4]:

$$
\log \mathrm{SPF}=\frac{\text { AUCtotal }}{\lambda \mathrm{n}-\lambda 1} \times 2
$$

$\lambda \mathrm{n}$ : The largest wavelength (at $\mathrm{A}=0.05$ )

$\lambda 1$ : The smallest wavelength $(290 \mathrm{~nm})$

\section{RESULTS}

\section{Total Flavonoid Content}

Determination flavonoid showed that flavonoid content in mulberry root extract was $0.22 \%$.

\section{Morfology of Nanoparticle mulberry extract}

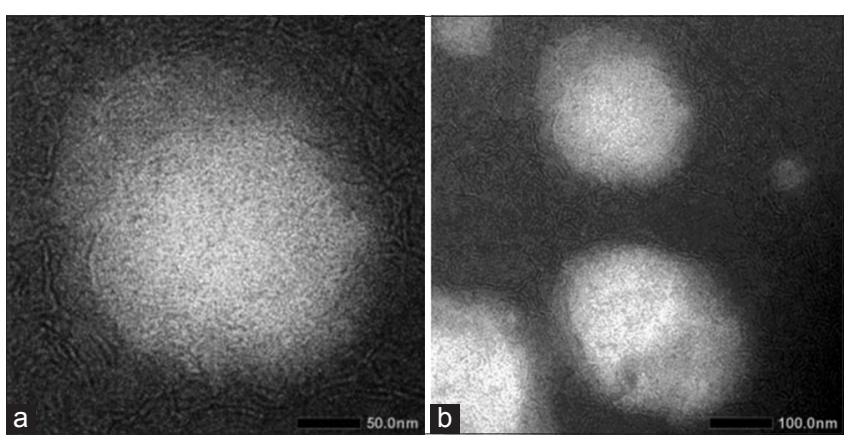

Fig. 1: ( $a$ and $b$ ) Transmission electron microscopy micrographs of nanostructured lipid carrier mulberry extract

\section{SPF of Crude Extract and NLC Based Gel}

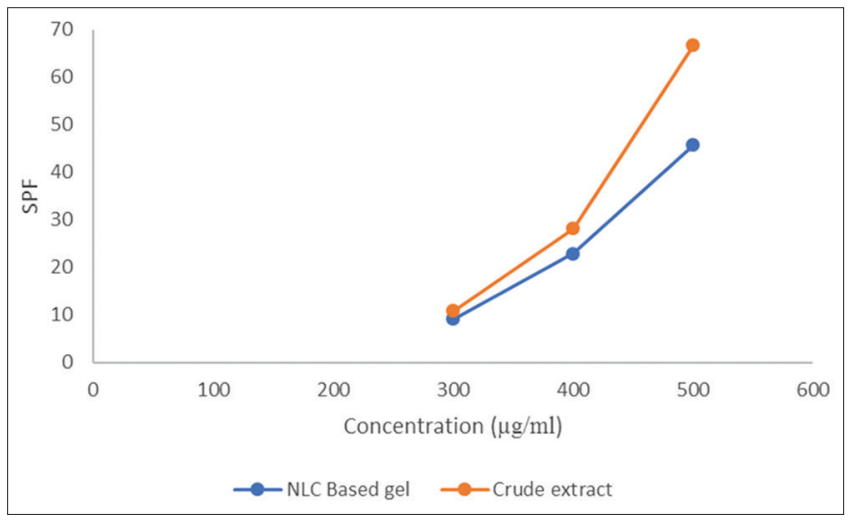

Fig. 2: Sun protection factor (SPF) of the ethanolic extract of Morus alba and nanostructured lipid carrier-based gel

\section{DISCUSSION}

The result of total flavonoid determination showed that total flavonoid content in mulberry root extract was $0.22 \%$. UV radiation will initiate photooxidative reactions. Flavonoids have good antioxidant activity so that it can inhibit the photooxidative reaction [5]. The extract of root mulberry was also known to contain stilbene groups which can inhibit increased level of lipid peroxidation and COX-2 activity [1].

Preparation NLC of mulberry root extract by solvent diffusion method

The NLC of mulberry root extract with 1:7 mix lipid - surfactant ratio was prepared by solvent diffusion method. The average particle size of the NLC dispersion was estimated to be $145.5 \mathrm{~nm}$ with a polydispersity index of 0.227 and zeta potential of $32.3 \mathrm{mV}$. The result of TEM imaging of NLC as shown in Fig. 1 indicated that the particles presented spherical shapes.

\section{Physicochemical characterization of NLC-based gel}

NLC-based gel was prepared by dispersing NLC crude extract to $0.3 \%$ carbopol gel base. The NLC-based gel characterization results as follows gel light yellow, viscous liquid, odorless, and homogeneous. NLC-based gel has a viscosity value of $42,666 \pm 1.24 \mathrm{cPs}$, plastic thixotropic flow properties, spreadability $5165.76 \pm 1.34 \mathrm{~mm}$, and pH 5.89 \pm 0.08 .

Sun protection factor (SPF) of the crude extract and NLC-based gel The ethanolic extract of Morus alba as photoprotective evaluated with the method developed by Petro et al., 1981. The results of the determinations of in vitro SPF values are shown in Fig. 2 . The SPF value of the extract and NLC-based gel depends on the concentration, the increase of the extract concentration resulted in an increasing of 
the SPF value. According to the National Agency of Drug and Food Control, Republic of Indonesia, only SPF value $\geq 15$ is suitable for use in cosmetic products with photoprotective activity. The mulberry extracts with different concentrations $(400$ and $500 \mu \mathrm{g} / \mathrm{mL}$ ) could meet the SPF values that must be $\geq 15$ so that the root extract of mulberry is potentially used as a sunscreen. There are several aspects that affect the difference of SPF value on extract and NLC-based gel, i.e., the combination and concentration of the ingredient; the effect and interactions of diluents such as surfactant used in the formulations; the $\mathrm{pH}$ system and also excipients and other active ingredients can also produce UV absorption bands, thus interfering with those of UV A and UV B sunscreens [6].

Nanoparticles of sunscreen have several advantages, that is, provide better stability of chemically unstable active ingredients, controlled release of active ingredients, and improve skin hydration and protection through the formation of films on the skin. Amount of molecular sunscreen could be decreased by $50 \%$ maintaining the protection compared with a conventional emulsion $[1,7]$.

\section{CONCLUSION}

Extracts of ethanol and NLC root gel mulberry (M. alba L.) have potential effectiveness as photoprotective. This research is being continued with study of mulberry roots as in vivo photoprotective and its safety as a cosmetic preparation.

\section{ACKNOWLEDGMENT}

The authors acknowledge the financial support received from Ministry of Research and Technology-Directorate of Higher Education (Kemenristek-DIKTI), for their support and encouragement in carrying out his college work.

\section{REFERENCES}

1. Saraf S, Kaur CD. Phytoconstituents as Photoprotective Novel Cosmetic Formulations. 2010;47:1-11. Available from: https://www. researchgate.net/publication/215908316.

2. Bonina F, Lanza M, Montenegro L, Puglisi C, Tomaino A. Flavonoid as potensial protective agent photooxidative skin damage. Int $\mathrm{J}$ Pharm 1996; 145:87-94

3. Soares LL, Bassani VL, Ortega G, Petrovick PR. Total flavonoid determination for the quality control of aqueous extractives from Phyllanthus niruri L. Lat. Am J Pharm 2003;22:203-7.

4. Petro AJ. Correlation of spectrophotometric data with sunscreen protection factors. Int J Cosmetic Sci 1981;3;185-96.

5. Gao Z, Huang K, Xu H. Protective effects of flavonoids in the roots of Scutellaria baicalensis Georgii against hydrogen peroxideinduced oxidative stress in HS-SY5Y cells. Pharmacol Res 2001;43:173-8.

6. Imam S, Azhar I, Mahmood ZA. In-vitro evaluation of sun protection factor of a cream formulation prepared from extracts of Musa Accuminata (1.), Psidium Gujava (1.) and Pyrus Communis (1.). Asian J Pharm Clin Res 2015;8:234-7.

7. Morganti P. Use and potential of nanotechnology in cosmetic dermatology. Clin Cosmet Investig Dermatol 2010;3:5-13. 